\title{
Pharmacoeconomic considerations in the treatment of breast cancer
}

This article was published in the following Dove Press journal:

ClinicoEconomics and Outcomes Research

14 June 2010

Number of times this article has been viewed

\author{
Athanasios Pallis' \\ Vasiliki Tsiantou ${ }^{2}$ \\ Efi Simou ${ }^{3}$ \\ Nikos Maniadakis ${ }^{4}$ \\ 'Department of Medical \\ Oncology, University General \\ Hospital of Heraklion, Crete; \\ ${ }^{2}$ Department of Health Economics, \\ ${ }^{3}$ Department of Epidemiology \\ and Biostatistics; ${ }^{4}$ Department of \\ Health Services Organization and \\ Management, National School of \\ Public Health, Athens, Greece
}

\begin{abstract}
Breast cancer is the most common malignancy in women worldwide and causes great economic burden. The aim of this paper is to present the available clinical and pharmacoeconomic evidence associated with different therapies for breast cancer. As significant progress was made in recent years and there are many alternative treatments, which are indicated according to the stage and the type of the disease, the age and health status of patient, and vary from surgery to hormonal treatment and chemotherapy. A broad literature review was undertaken and the paper presents the evidence available regarding the effectiveness and cost-effectiveness of the alternative options. Despite the high cost of most therapies and perceptions that treatments in this area may not be cost-effective, due to a combination of high costs and short survival, based on the literature review treatment options for breast cancer are in general deemed to be cost-effective. Time horizon, stage of the disease, patient age, therapy onset, benefit duration and time to recurrence may influence the results. Pharmacoeconomic analyses of alternative therapy options will improve decision-making and will help to optimize the use of scarce health care resources allocated to the care of breast cancer patients.
\end{abstract}

Keywords: breast cancer, cost, pharmacoeconomics

\section{Introduction}

Breast cancer is the uncontrolled, abnormal growth of malignant breast tissue. It is the second most common nonskin cancer, with approximately 430,000 cases occurring each year in Europe. ${ }^{1}$ It is also the second leading cause of cancer-related death in women in the Western world after lung cancer, ${ }^{2}$ with about 132,000 deaths each year and a five-year overall survival of $79.5 \% .^{3}$

Current treatment options for breast cancer depend on disease characteristics (ie, stage, grade, Her-2 status, number of positive lymph nodes, hormone receptor status of the tumor) and on patient characteristics (such as age and menopausal status).

This paper aims at incorporating two distinct, yet important, features of oncology. Firstly, clinical concepts related to the treatment of breast cancer with hormone therapy and chemotherapy and, secondly, a pharmacoeconomic evaluation of the various approaches to the treatment of this common disease.

\section{Epidemiology}

Globally, breast cancer incidence rates are highest in North America and northern Europe, and lowest in Asia and Africa. ${ }^{4}$ Incidence rates in Japan and urban China have been rising in recent years. These international differences are thought to be related to societal changes occurring during industrialization (eg, changes in fat intake, body
Correspondence: Nikos Maniadakis realth Services Management, Nationz and Mation School of Public Health, I 96 Alexandras Avenue, II52I Athens, Greece Tel +306945237716

Fax +302107227222

Email nmaniadakis@esdy.edu.gr 
weight, age at menarche, and/or lactation, and reproductive patterns, such as fewer pregnancies and later age at first birth).

The lifetime probability of developing breast cancer is one in six overall (one in eight for invasive disease). Previous breast cancer, early menarche, late menopause, hormone replacement therapy, oral contraception, obesity, and alcohol consumption are associated with an increased risk of breast cancer. Although the majority of breast cancer cases occur in women who have no family history of the disease, family history and genetic predisposition also play an important role, because women who carry mutations of breast cancer susceptibility genes (BRCA1 or 2) are at a higher risk of developing breast cancer. ${ }^{5}$

The incidence of breast cancer increases rapidly with age during the reproductive years and then increases at a slower rate after about age 50, the average age at menopause. The cumulative incidence of breast cancer among women in Europe and North America is about $2.7 \%$ by age 55, about $5.0 \%$ by age 65 , and about $7.7 \%$ by age 75.6 Incidence rates are high in more developed countries, whereas rates in less developed countries are low but increasing. ${ }^{7}$

About $20 \%$ of all breast cancer cases occur in women younger than 50 years of age (premenopausal) and $60 \%$ of these cases are estrogen receptor-positive, compared with $80 \%$ being estrogen receptor-positive in women older than 50 years (postmenopausal). ${ }^{8}$ Breast tissue contains receptors for the female hormones estrogen and progesterone. These receptors allow the breast tissue to grow or change in response to changing levels of those hormones.

Breast cancer is a disease with a great epidemiologic and economic burden. The total cost of breast cancer includes not only the medical cost (ie, cost of screening, prevention, pharmaceutical treatment, surgical intervention, and palliative care) but also the indirect cost of the disease in terms of lost productivity and premature deaths, given that a significant percentage of the prevalence of breast cancer affecting women younger than 50 years of age.

\section{Economic burden}

The majority of studies that report the financial burden of breast cancer take into account the payer's perspective, whereas the estimation of the societal cost of the disease is less commonly investigated. However, estimations of the total cost show that the direct cost is the smallest contributor to the total cost per patient, being dependent on the stage of the disease, the therapeutic intervention, and the patient's age. Evidence from multiple studies has shown that the cost increases with the stage of the disease and age. In addition, differences in the cost per patient may also arise from alternative therapeutic schemes.

A review of the published studies of the cost of illness arising from breast cancer in the US concluded that the lifetime cost per patient varied between US\$20,000 and US $\$ 100.000$, with chemotherapy being the greatest driver of the total direct cost. ${ }^{9}$ A more recent study regarding the assessment of cost and resource utilization of breast cancer patients in US concluded that the mean monthly cost per patient was US $\$ 2,896$, driven mainly by costs attributable to hospitalization, and followed by pharmacotherapy costs, and costs of surgical interventions. ${ }^{10}$ In California the total economic cost of breast cancer (indirect cost was included) was US\$1.43 billion in 2001. ${ }^{11}$

In Sweden, the findings of a study that attempted to estimate the cost of breast cancer confirmed, as expected, that an increased stage of disease translates into increased resource use and cost. Specifically, the annual total cost for patients with metastatic breast cancer was US\$46,500. However, the researchers concluded that the indirect cost was lower for patients older than 65 years. ${ }^{12}$ This finding can be partly explained by the fact that people younger than 65 years are still working, so that the cost of lost productivity due to sick leave, early retirement, and premature mortality is greater. ${ }^{13}$

The treatment of metastases is also a significant contributor to the total cost of breast cancer. ${ }^{14,15}$ In the US it was estimated that the mean total cost of a metastatic breast cancer patient was almost nine times greater than for a noncancer patient. ${ }^{16}$ Finally, the economic burden of surviving breast cancer ${ }^{17}$ or breast cancer recurrence ${ }^{18}$ is also of great importance, mostly as regards the overuse of medical resources for followup.

\section{Efficacy of therapy Surgical treatment}

Surgery is the cornerstone of management of early breast cancer. Breast cancer surgery has significantly evolved during the last decades. The operation evolved from radical mastectomy to modified radical mastectomy and to "skin-sparing" mastectomy, introduced in $1991 .{ }^{19}$ The introduction of radiotherapy (RT) and its success in eliminating subclinical foci of disease allowed the development of breast conservation therapy (BCT). With the emergence of BCT, women with invasive breast cancer may now preserve their breast without compromising the oncological outcome. Several prospective randomized clinical trials have demonstrated 
Table I Preferred regimens for the adjuvant treatment of early breast cancer

TAC regimen $^{88}$

Docetaxel $75 \mathrm{mg} / \mathrm{m}^{2}$ day I

Doxorubicin $50 \mathrm{mg} / \mathrm{m}^{2}$ day I

Cyclophosphamide $500 \mathrm{mg} / \mathrm{m}^{2}$ day I

Every 21 days for six cycles

AC regimen ${ }^{89}$

Doxorubicin $60 \mathrm{mg} / \mathrm{m}^{2}$ day I

Cyclophosphamide $600 \mathrm{mg} / \mathrm{m}^{2}$ day I

Every 21 days for four cycles

AC followed by paclitaxel regimen ${ }^{90-92}$

Doxorubicin $60 \mathrm{mg} / \mathrm{m}^{2}$ day I

Cyclophosphamide $600 \mathrm{mg} / \mathrm{m}^{2}$ day I

Every 2 I days for four cycles followed by paclitaxel $175 \mathrm{mg} / \mathrm{m}^{2}$ weekly for 12 weeks

Dose-dense AC followed by paclitaxel ${ }^{93}$

Doxorubicin $60 \mathrm{mg} / \mathrm{m}^{2}$ day I

Cyclophosphamide $600 \mathrm{mg} / \mathrm{m}^{2}$ day I

Every 14 days for four cycles followed by paclitaxel $175 \mathrm{mg} / \mathrm{m}^{2}$ day I every 14 days for four cycles

\section{AT regimen ${ }^{94}$}

Doxorubicin $60 \mathrm{mg} / \mathrm{m}^{2}$ day I

Docetaxel $60 \mathrm{mg} / \mathrm{m}^{2}$ day I

Every 21 days, for four cycles

TC regimen ${ }^{95}$

Docetaxel $75 \mathrm{mg} / \mathrm{m}^{2}$ day I

Cyclophosphamide $600 \mathrm{mg} / \mathrm{m}^{2}$ day I

Every 21 days, for four cycles

EC regimen ${ }^{96}$

Epirubicin $100 \mathrm{mg} / \mathrm{m}^{2}$ day I

Cyclophosphamide $830 \mathrm{mg} / \mathrm{m}^{2}$ day I

Every 21 days, for eight cycles

FAC regimen ${ }^{97,98}$

5-Fluorouracil $500 \mathrm{mg} / \mathrm{m}^{2}$ days I and 8

Doxorubicin $50 \mathrm{mg} / \mathrm{m}^{2}$ day I

Cyclophosphamide $500 \mathrm{mg} / \mathrm{m}^{2}$ day I

Every 21 days, for six cycles

FEC regimen"9

5 -Fluorouracil $500 \mathrm{mg} / \mathrm{m}^{2}$ days I and 8

Epirubicin $60 \mathrm{mg} / \mathrm{m}^{2}$ days $\mathrm{I}$ and 8

Cyclophosphamide $75 \mathrm{mg} / \mathrm{m}^{2}$, po, days I-14

Every 21 days for six cycles

FEC followed by docetaxel 100

5 -Fluorouracil $500 \mathrm{mg} / \mathrm{m}^{2}$ day I

Epirubicin $100 \mathrm{mg} / \mathrm{m}^{2}$ day I

Cyclophosphamide $500 \mathrm{mg} / \mathrm{m}^{2}$ day I

Every 2 I days, for three cycles followed by docetaxel $100 \mathrm{mg} / \mathrm{m}^{2}$ day I every 21 days for three cycles

(Continued)
Table I (Continued)

FEC followed by paclitaxel ${ }^{101}$

5 -Fluorouracil $600 \mathrm{mg} / \mathrm{m}^{2}$ day I

Epirubicin $90 \mathrm{mg} / \mathrm{m}^{2}$ day I

Cyclophosphamide $600 \mathrm{mg} / \mathrm{m}^{2}$ day I

Every 2 I days, for three cycles followed by paclitaxel $100 \mathrm{mg} / \mathrm{m}^{2}$ weekly for eight weeks

CMF regimen

Cyclophosphamide $100 \mathrm{mg} / \mathrm{m}^{2}$, po, days $\mathrm{I}-14$

Methotrexate $40 \mathrm{mg} / \mathrm{m}^{2}$ days I and 8

5 -Fluorouracil $600 \mathrm{mg} / \mathrm{m}^{2}$ days I and 8

Every 28 days, for six cycles

Abbreviations: TAC, docetaxel-doxorubicin-cyclophosphamide; AC, doxorubicincyclophosphamide; AT, doxorubicin-docetaxel; TC, docetaxel-cyclophosphamide; EC, epirubicin-cyclophosphamide; FAC, 5-fluorouracil-doxorubicin-cyclophosphamide; FEC, 5-fluorouracil-epirubicin-cyclophosphamide; CMF, cyclophosphamide-methotrexate5 -fluorouracil; po, oral.

equivalent survival outcome between mastectomy and $\mathrm{BCT} .^{20}$ ${ }^{24}$ The absolute contraindications for BCT include a history of prior therapeutic RT, which would result in an excessively high total radiation dose to the chest wall; multicentric disease (two or more primary tumors in separate quadrants of the breast); and diffuse, malignant-appearing microcalcifications on mammography. Pregnancy is an absolute contraindication to the use of breast irradiation: however, it may be possible to perform breast-conserving surgery in the third trimester, deferring breast irradiation until after delivery. Relative contraindications to BCT include connective tissue disease, which results in poor tolerance of RT, and a sizeable tumor in a smaller breast where the subsequent cosmetic outcome would be unacceptable.

Axillary lymph node dissection (ALND) has traditionally been standard practice in the surgical management of early breast cancer. The benefits of ALND include its impact on disease control (ie, axillary recurrence and survival), while it also has significant prognostic value and plays an important role in treatment selection. Histological examination of removed lymph nodes at the time of ALND is thought to be the most accurate method for assessing the spread of disease to these nodes. In order to avoid the negative impact of ALND on quality of life, the sentinel lymph node (SLN) technique has been developed. This technique is increasingly being used as a method to determine whether full ALND is necessary. For patients who undergo SLN biopsy rather than initial ALND, completion ALND continues to be the standard treatment recommendation if the SLNs are positive. ${ }^{25}$ The SLN technique should not be used in women with palpable axillary lymph nodes and in patients with inflammatory breast cancer. 


\section{Hormonal treatment}

For patients with hormone receptor-positive tumors, hormonal treatment is one of the first choices for treatment. ${ }^{6,26}$ Hormonal therapy acts by depriving the tumor cells of the proliferative stimulus provided by estrogen. This can be achieved by blocking the binding of estrogen to its receptor in the nucleus of responsive cells, as with tamoxifen. In premenopausal women, estrogens are directly produced in the ovaries until production declines during the menopause. After the menopause, estrogens are still produced (to a lesser extent) in nonovarian tissues, such as muscle and fat, by the enzyme aromatase, which converts androgens secreted by the adrenal cortex into estrogens. Aromatase inhibitors block the conversion of androgens to estrogens in the peripheral tissues in postmenopausal women, thereby reducing plasma levels of estrogens. ${ }^{27}$

Given the high incidence of estrogen receptor-positive breast cancer, it is clear that advances in endocrine treatment have the potential to result in significant decreases in breast mortality. Tamoxifen is one of the most studied agents in the treatment of estrogen receptor-positive breast cancer in both adjuvant and advanced disease settings. Tamoxifen provides protection against bone fractures in postmenopausal women and also lowers serum cholesterol levels. However, the long-term use of tamoxifen may be associated with vaginal bleeding, endometrial thickening, and increased risk of endometrial cancer and thromboembolic events.

Although tamoxifen has been the backbone of hormonal treatment for both pre- and postmenopausal women, ${ }^{28,29}$ several randomized Phase III trials have evaluated the role of aromatase inhibitors in women with hormone receptorpositive breast cancers, either in the adjuvant $t^{30-41}$ or in the advanced ${ }^{42-46}$ disease setting. Although it is clear that aromatase inhibitors offer a significant benefit in terms of disease-free survival when compared with tamoxifen, it is not clear which approach is the most effective, ie, initial use of aromatase inhibitors, sequential use after 2-3 years of tamoxifen, or extended use after five years of tamoxifen. Although cross-study comparisons have severe limitations, trials evaluating the sequential approach report a hazard ratio ranging from 0.57 to 0.76 , while the upfront approach results in a hazard ratio of $0.82-0.87$. Thus, one could argue that the sequential approach is more effective. Although upfront trials do not report a survival benefit in favor of aromatase inhibitors, a pooled analysis of the ARNO 95, ABCSG 8, and ITA trials reported a survival benefit for the sequential approach. ${ }^{47}$

\section{Chemotherapy}

Chemotherapy is used in the treatment of both hormone receptor-positive and -negative patients in the adjuvant and advanced disease settings. Chemotherapy offers benefits in terms of symptom control, quality of life, and survival, and is considered the treatment of choice for many patients. However, it is also associated with significant toxicity. A number of different chemotherapy drugs, or classes of drug, are effective, including anthracyclines (doxorubicin, epirubicin), taxanes (docetaxel and paclitaxel), capecitabine, vinorelbine, gemcitabine, alkylating agents such as cyclophosphamide, and platinum-based drugs such as carboplatin.

\section{Adjuvant chemotherapy}

Adjuvant chemotherapy should be considered after definitive surgical treatment. The published results of the Early Breast Cancer Trialists' Collaborative Group overview analysis have clearly demonstrated that adjuvant polychemotherapy results in substantial reductions in the risk of recurrence and death from breast cancer in all age groups under the age of 70 years. ${ }^{6}$ The decision whether or not to administer adjuvant chemotherapy should take into account the estimated absolute benefit, the patient's life expectancy, the presence or absence of prognostic factors, treatment tolerance, and patient preferences.

A number of prognostic factors have been associated with the risk of recurrence or death from breast cancer. The strongest prognostic factors are the patient's age, tumor size, tumor grade, number of lymph nodes involved, Her-2 status, peritumoral vascular invasion, and hormonal receptor status. ${ }^{26,27}$ The absolute benefit of chemotherapy therefore varies according to both the patient's age and underlying prognostic factors.

According to the National Comprehensive Cancer Network (NCCN) guidelines, ${ }^{48}$ patients with lymph node involvement or with tumors greater than $1 \mathrm{~cm}$ in diameter are appropriate candidates for adjuvant systemic therapy. On the other hand, the St Gallen International Expert Consensus takes into account all the above-mentioned prognostic factors in order to recommend adjuvant chemotherapy or not. ${ }^{26}$ Furthermore, recent advances in DNA microarray technologies has allowed the development of classification systems of breast cancer by gene expression profile. ${ }^{49}$ Five major subtypes of breast cancer have been identified by DNA gene expression profiling: estrogen receptor-positive/Her-2 negative (luminal A and luminal B subtypes); estrogen receptor-negative/Her-2 negative (basal subtype); Her-2 positive; and normal breast-like tumors. ${ }^{49}$ In retrospective analyses, these profiles were found to be associated with the risk of relapse and death from breast cancer. 
This approach could possibly be used for decision-making in adjuvant treatment of breast cancer patients, but it needs to be validated prospectively.

Despite the high incidence of breast cancer and the extensive research in this field, no chemotherapy regimen can be considered as "standard" treatment for early breast cancer. Preferred adjuvant regimens according to NCCN guidelines are presented in the Table. ${ }^{48}$ Allocation to about six months of anthracycline-based polychemotherapy (eg, with fluorouracildoxorubicin-cyclophosphamide or fluorouracil-epirubicincyclophosphamide) reduces the annual breast cancer death rate by about $38 \%$ for women younger than 50 years when diagnosed and by about $20 \%$ for those aged 50-69 years when diagnosed, largely irrespective of the use of tamoxifen and of estrogen receptor status, nodal status, or other tumor characteristics. Such regimens are significantly $(P=0.0001$ for recurrence, $P<0.00001$ for breast cancer mortality) more effective than cyclophosphamide-methotrexate-5-flurouracil chemotherapy. ${ }^{6}$ Similarly, the inclusion of taxanes in the adjuvant treatment of breast cancer resulted in a $17 \%$ reduction in the risk of relapse $(P<0.00001)$ and a $15 \%$ reduction in the risk of death $(P<0.00001)$ compared with taxane-free regimens. ${ }^{50}$

\section{Advanced disease}

Compared with the treatment options for early-stage breast cancer, few data exist regarding the optimal use of chemotherapy for metastatic breast cancer (MBC). A variety of chemotherapy agents, either as single-agent or combination regimens, are considered effective in the treatment of MBC: anthracyclines (doxorubicin, epirubicin, liposomal doxorubicin), taxanes (paclitaxel, docetaxel), antimetabolites (gemcitabine, capecitabine), and microtubule inhibitors (vinorelbine). A significant but still controversial issue in the treatment of $\mathrm{MBC}$ remains the choice between using a combination of cytotoxic chemotherapies or sequential single agents. ${ }^{51}$ Combination regimens result in higher response rates and a longer time to tumor progression (TTP) compared with sequential single agents; however, they do not offer substantial survival benefit. ${ }^{52,53}$ Furthermore, combination treatment is associated with significantly higher toxicity and adverse events. ${ }^{54}$ On the basis of available data, sequential monotherapy is recommended as the preferred choice in advanced disease, in the absence of rapid clinical progression, life-threatening visceral metastases, or the need for rapid symptom and/or disease control. ${ }^{48,51}$

A recently published study randomly allocated 715 women with $\mathrm{MBC}$ to first-line chemotherapy with paclitaxel with or without bevacizumab, a humanized monoclonal antibody against vascular endothelial growth factor. ${ }^{55}$ This trial yielded a significant prolongation of TTP in favor of bevacizumab, but failed to show a statistically significant difference in terms of overall survival.

\section{Trastuzumab in Her-2 positive disease}

Her-2/neu is a member of the erb family and is a proto-oncogene located on chromosome $17 q 21$. Approximately $18 \%$ to $20 \%$ of breast cancers have amplification and/or overexpression of this gene, which encodes the cell surface molecule HER2, a transmembrane glycoprotein receptor with tyrosine kinase activity. ${ }^{56}$ Trastuzumab (Herceptin, Genentech, Roche) is a recombinant DNA-derived, chimeric, humanized monoclonal antibody that binds to the extracellular domain of Her- 2 .

Patients with Her-2 positive MBC should receive treatment with trastuzumab, either in combination with cytotoxic chemotherapeutic agents ${ }^{57-60}$ or as single agent. ${ }^{61}$ Patients with Her-2 positive MBC should continue anti-Her treatment after progression on first-line trastuzumab-containing regimens. Patients could continue trastuzumab following progression on trastuzumab-containing regimens, given that several trials have demonstrated a benefit. ${ }^{62,63}$ A recent Phase III trial demonstrated that the combination of lapatinib with capecitabine in patients with $\mathrm{MBC}$ refractory to trastuzumab offers a significant prolongation of TTP compared with capecitabine alone. ${ }^{64}$ Additionally, in heavily pretreated women with MBC refractory to trastuzumab, the combination of trastuzumab plus lapatinib resulted in a longer TTP compared with lapatinib monotherapy. ${ }^{65}$

Five randomized Phase III trials evaluated the role of trastuzumab in combination with chemotherapy as adjuvant treatment in early breast cancer. ${ }^{66-69}$ All these trials demonstrated a statistically significant reduction in the risk of relapse and some of them also reported a survival benefit. ${ }^{66,67}$ On the basis of these trials trastuzumab is recommended for Her-2 positive tumors $\geq 1 \mathrm{~cm} .{ }^{48}$ It is not clear whether trastuzumab should be administered for one year ${ }^{66,67,69}$ or for a shorter period on the basis of the FinHer trial. ${ }^{68}$

\section{Metastatic bone disease}

Metastatic bone disease is one of the most common metastases in breast cancer. Breast cancer patients with bone metastatic disease should be treated with bisphosphonates. ${ }^{70}$ Bisphosphonate treatment is associated with fewer skeletal-related events, pathological fractures, and less need for radiation treatment and surgery to treat bone pain. ${ }^{71-73}$ Bisphosphonate treatment is given in addi- 
tion to chemotherapy or hormonal therapy, but it should be underlined that bisphosphonate is a palliative measure and does not offer a survival benefit.

\section{Adverse effects}

Hot flushes are a common side effect of both tamoxifen and aromatase inhibitors, although they occur more frequently in patients receiving aromatase inhibitors. ${ }^{29}$ Arthralgias are also more frequent in patients receiving aromatase inhibitors compared with tamoxifen and their incidence ranges from $18 \%$ to $36 \%$ in clinical trials. ${ }^{29}$ However, the mechanism by which arthralgias are created is not clearly understood. Furthermore, studies designed to look at the effect of aromatase inhibitors on bone mineral density have shown a significant decrease in bone mineral density in the aromatase inhibitor groups compared with placebo groups and hence an increase in the incidence of fractures in comparison with tamoxifen. ${ }^{74}$ With respect to cardiovascular disease, although tamoxifen is considered to be cardioprotective, it is not clear whether aromatase inhibitors are associated with a higher incidence of cardiovascular events. The BIG 1-98 study reported an increase in cardiovascular events compared with tamoxifen, ${ }^{32}$ while the MA.17 study reported no difference. ${ }^{75}$

Adjuvant treatment with a combination of trastuzumab and chemotherapy has been associated with a significant increase in the risk of congestive heart failure and arrhythmias. ${ }^{76,77}$ In the above-mentioned trials, the percentage of severe (Class III/IV) congestive heart failure, or cardiacrelated death for patients receiving trastuzumab ranged from $0 \%$ (59) to $4.1 \% .{ }^{77}$ Additionally, concerns have been raised about the long-term cardiac risks in patients receiving trastuzumab, based on a longer followup. ${ }^{78}$

Brain metastases are increasingly being reported as the site of first relapse in women with breast cancer who are receiving trastuzumab for Her-2-overexpressing disease. A trend towards a higher number of central nervous system metastases as the first event in the trastuzumab-containing arms has been reported for the N9831/NSABP B-31 ${ }^{66}$ and HERA $^{67}$ trials. However, it seems unlikely that the use of trastuzumab in the adjuvant setting "increases" the risk of brain metastases. ${ }^{79}$ It is more likely that the central nervous system represents a sanctuary site due to the inability of trastuzumab to cross the blood-brain barrier.

\section{Economic analysis}

In order to evaluate the cost-effectiveness of the various approaches to the treatment of breast cancer, we undertook a literature review of recently published studies evaluating the aforementioned therapies. The terms "breast cancer" and "cost" were used as key words in the various databases. The search was limited to articles published from 1999 to 2009 and included only English language studies. Studies which evaluated the cost-effectiveness of screening programs, diagnostic techniques, and effectiveness of alternative treatments were excluded from the review. Studies that had not undertaken an original economic evaluation and reported results from literature reviews only were also excluded. The remaining studies were classified into two categories, ie, those that reported the economic burden of the disease and those that evaluated the cost-effectiveness of the treatments. The pharmacoeconomic evaluations were classified based on the substance used for treatment.

Overall, the majority of the studies present unanimity regarding the methodology followed. Cost-effectiveness analysis and the development of a Markov model were the most popular methodologic approaches in the studies reviewed. Quality-adjusted life years (QALYs) and life years gained (LYG) were the preferred measures of benefit, while the majority of the studies were carried out under the third-party payer or health system perspective. All studies performed a sensitivity analysis in order to investigate the robustness of their results. The parameters that seem to be the most influential are the time horizon, stage of the disease, age of the patient, as well as time of therapy initiation, duration of benefits and time to recurrence.

\section{Cost-effectiveness of drug therapy Tamoxifen}

Tamoxifen is used for both the prevention and the treatment of breast cancer. The use of tamoxifen therapy over a five-year period has been proved to be cost-effective regarding breast cancer risk reduction. The incremental cost per QALY gained was Aus $\$ 38,271 .^{80} \mathrm{~A}$ cost-utility analysis compared tamoxifen with tamoxifen plus chemotherapy as adjuvant therapy in postmenopausal women with early breast cancer in the UK. Tamoxifen plus chemotherapy was more effective but at the same time more expensive compared with tamoxifen alone. The incremental cost per QALY gained was $£ 3,483$, indicating that the combination of tamoxifen with chemotherapy was cost-effective. ${ }^{81}$

\section{Aromatase inhibitors}

The majority of the pharmacoeconomic evaluations identified in our review concerned aromatase inhibitors, both nonsteroidal (anastrozole, letrozole) and steroidal (exemestane). 
Assessment of sequential use of exemestane after two or three years of tamoxifen in postmenopausal women with early-stage breast cancer was the main objective in several economic evaluations. Even though the time horizon of the studies was different, as was the currency used, the conclusion was the same in all studies, and demonstrated that sequential treatment with exemestane was cost-effective. The incremental cost per QALY gained was estimated at US\$20,100 in the USA, ${ }^{82}$ Can $\$ 24,185$ in Canada, ${ }^{83}$ and $€ 20,000$ in Sweden. ${ }^{84}$

In the case of advanced breast cancer the use of exemestane instead of megestrol was cost-effective. In the US the incremental cost per LYG was US\$10,600 85 while in Europe it was ranged from $€ 3,700$ in Germany to $€ 9,091$ in the Netherlands. ${ }^{86}$ Similarly, letrozole represents a cost-effective alternative to megestrol in the UK National Health Service (NHS) setting, with an incremental cost per LYG of $£ 3,588 .{ }^{87}$

\section{Chemotherapy}

Taxanes are a therapeutic class used in chemotherapy. Taxanes can be administered as single agents or in combination with other taxanes, antimetabolites, or anthracyclines.

A recent economic evaluation of the cost-effectiveness of taxanes in the adjuvant treatment of breast cancer reported a cost per QALY for taxane compared with nontaxane-containing chemotherapy of $£ 12,000-£ 43,000$, depending on the taxane under consideration and the specific trial used as the basis of the analysis. ${ }^{88}$ A cost-utility analysis in Thailand assessed the cost effectiveness of doxorubicin-cyclophosphamide adjuvant therapy versus cyclophosphamide-paclitaxel in women with early-stage breast cancer. Although the estimated benefits for the patient were better in the case of the combination therapy, the incremental cost per QALY was THB738,111 ( $\sim$ US\$22,250), thus prohibiting the implementation of this therapy in Thailand. ${ }^{89}$

In the UK in 2001, a Markov model was designed to assess the cost-utility ratios of three different taxanes in patients with advanced breast cancer. ${ }^{90}$ Docetaxel was the most costeffective treatment compared with paclitaxel and vinorelbine. The incremental cost for docetaxel per QALY gained was $£ 1,995$ over paclitaxel and $£ 14,055$ over vinorelbine. A similar study was carried out in Canada, where the study population was patients with metastatic breast cancer. The average cost per quality-adjusted progression-free survival ranged from Can $\$ 31,220$ for vinorelbine to Can $\$ 110,072$ for docetaxel..$^{91}$ A more recent study of the cost-effectiveness of docetaxel over paclitaxel for the treatment of MBC patients reported that docetaxel was a cost-effective therapy, with an incremental cost per LYG of Can $\$ 30,337 .{ }^{92}$ Another study compared taxanes with standard second-line chemotherapy in patients with MBC. The cost-utility analysis showed that the cost per QALY ranged from US\$13,922 for standard chemotherapy to US\$49,739 for docetaxel. The authors reported that, although current chemotherapy was the cheapest approach, it offered the least number of LYG. Thus, the best alternative was vinorelbine-mytomycin $\mathrm{C}$ therapy. ${ }^{93}$

A common therapeutic scheme in chemotherapy is the combination of taxanes with antimetabolites, and especially the use of capecitabine combined with docetaxel as therapy for the treatment of MBC. In our review, three different studies evaluating this treatment scheme in comparison with single-agent taxane therapy were identified and they reported that the combination therapy was costeffective in the treatment of MBC. ${ }^{94-96}$ A Markov model was developed to estimate the cost-effectiveness of gemcitabine-paclitaxel in patients with $\mathrm{MBC}$ and reported an incremental cost-effectiveness ratio (ICER) of $£ 38,699$ per QALY gained, which is higher than the threshold defined by the NHS. ${ }^{97}$

Despite the high incidence of breast cancer and the great amount of data in the field of first-line therapy, limited economic evidence is available about the cost-effectiveness of the various treatment options presented. An economic evaluation for first-line sequential therapy was reported by the National Institute for Health and Clinical Excellence (NICE). ${ }^{98}$ The scenario studied considered that all patients would have been treated with anthracyclines in the adjuvant setting. The analysis showed that the most cost-effective treatment sequence, based on a threshold of $£ 30,000$ per QALY, was docetaxel monotherapy followed by capecitabine monotherapy followed by vinorelbine monotherapy. The ICER for this sequence was estimated to be $£ 23,332$ per QALY. When applying a threshold of $£ 20,000$ per QALY, the most cost-effective sequence was docetaxel monotherapy followed by capecitabine monotherapy, followed by no further chemotherapy.

\section{Trastuzumab}

A recently published systematic review evaluated the cost-effectiveness of adjuvant trastuzumab treatment. ${ }^{99}$ Cost-effectiveness ratios reported ranged from US\$5,020/ QALY to US\$134,610/QALY. Most studies reported favorable cost-effectiveness values (ie, below US\$50,000/ QALY). About 84.6\% were conducted using a Markov model based on data from clinical trials and $15.3 \%$ were analyzed by other economic or cost models; $84.6 \%$ reported 
sensitivity analysis, 11 studies (84.6\%) clearly described a justification for selecting the study design, and only $15.3 \%$ noted study limitations. A NICE guideline evaluated all the available data for trastuzumab adjuvant studies and estimated incremental costs per QALY gained with adjuvant trastuzumab treatment ranging from $£ 16,000$ to $£ 33,000 .{ }^{100}$ A cost-effectiveness analysis reported by Belgian health care authorities estimated the incremental cost-effectiveness ratio based on a lifetime simulation at $€ 10,315$ per QALY gained. ${ }^{101}$

The cost-effectiveness of trastuzumab in combination with standard treatment in HER-2 positive breast cancer patients was estimated in several studies identified in our review. The economic results and benefits differ based on the stage of the disease. However, both clinical and economic benefits were superior for the stage III patients. ${ }^{102}$ The authors of a Belgian study found that nine weeks of trastuzumab was dominant over no trastuzumab treatment. ${ }^{102}$ Similar results were reported by the authors of an Australian study, who found that nine weeks' trastuzumab was dominant over no trastuzumab, reporting an incremental cost of Aus $\$ 1,700$ per QALY gained for nine-weeks of trastuzumab compared with standard treatment alone. ${ }^{103}$

\section{Bisphosphonates}

Our review identified seven economic evaluations of bisphosphonates as a treatment intervention in metastatic bone disease. The majority of these studies compared third-generation bisphosphonates (zoledronic acid, ibandronate) with second-generation (pamidronate) or first-generation (clodronate) bisphosphonates. An economic study conducted in the UK compared five types of bisphosphonates with no treatment from the NHS perspective. According to the findings of the study, the use of bisphosphonates in the management of patients with bone metastases was cost-saving to the NHS. In fact, zoledronic acid was the dominant strategy of all the five types compared in the study. ${ }^{104}$

Two different studies assessed the economic consequences of zoledronic acid versus pamidronate as the therapeutic strategy in patients with at least one bone metastasis. The perspective of both studies was the health system, but the results were different. The first study was carried out in the UK and concluded that pamidronate was the preferred strategy because it could lead to a reduction of $11 \%$ in health care costs. ${ }^{105}$ The second was undertaken in Spain and the conclusion was that, although zoledronic acid was more expensive, its higher cost could be counterbalanced by the savings in infusion time and better outcomes. ${ }^{106}$

In the case of breast cancer patients who suffer from bone metastases and are concurrently undergoing oral hormonal therapy, oral ibandronate is the dominant treatment option compared with zoledronic acid and pamidronate. ${ }^{107}$ On the other hand, there are studies that, although agreeing that bisphosphonates (especially third-generation bisphosphonates ${ }^{108}$ ) are effective in the secondary prevention of bone complications in breast cancer metastases, conclude either that this strategy is too expensive ${ }^{109}$ or that the cost of providing it will be large given the prevalence of metastatic breast cancer. ${ }^{110}$

Overall, the costs of bisphosphonate therapy appear to be higher than the cost savings from the prevention of skeletal-related events. The costs per QALY have been estimated to be $>$ US\$100,000. ${ }^{111}$

\section{Aromatase inhibitors versus tamoxifen \\ Adjuvant setting Postmenopausal}

In postmenopausal women, the standard of care for hormone receptor-positive tumors was five years of tamoxifen. This approach was associated with a $40 \%$ reduction in the risk of recurrence and $34 \%$ reduction in the risk of death. ${ }^{6}$ Until recently, trials testing durations of tamoxifen longer than five years had not shown additional benefit, but the ATLAS (Adjuvant Tamoxifen, Longer Against Shorter) trial, showed a small but significant reduction in the risk of recurrence with 10 years compared with five years of tamoxifen therapy. ${ }^{112}$

However, during the last decade tamoxifen's role has been challenged by the aromatase inhibitors, namely letrozole, anastrozole (nonsteroidal) and exemestane (steroidal). In early breast cancer, and especially in postmenopausal women with hormone receptor-positive cancer, initial adjuvant therapy with letrozole was found to be cost-effective compared with tamoxifen, with an incremental cost per QALY of Can $\$ 23,662 .{ }^{113}$ Letrozole can be used as first-line therapy for advanced breast cancer and it is a cost-effective option. This was suggested by two different studies evaluating the costs and benefits of this treatment scheme. The first was carried out in Japan and showed a cost of US\$4,969 per LYG over tamoxifen, ${ }^{114}$ while the second yielded a cost per LYG of $£ 5,917 .{ }^{115}$

Similar results were reported from pharmacoeconomic studies investigating the cost-effectiveness of the use of anastrozole over tamoxifen in different countries. Even 
though the currency used was different, the conclusion was that anastrozole is a cost-effective choice as adjuvant therapy for early breast cancer. ${ }^{116-120}$ The use of letrozole in the extended adjuvant treatment was also proved to be cost-effective, yielding an ICER of Can\$34,058 per QALY in Canada ${ }^{121}$ and US\$28,728 per QALY in the US. ${ }^{122}$

Three different approaches have been tested against the "gold standard" of five years of tamoxifen, ie, upfront aromatase inhibitors, two to three years of tamoxifen followed by aromatase inhibitors for a total of five years, and extended treatment with sequential aromatase inhibitors after five years of tamoxifen.

Two large Phase III trials with more than 17,000 patients evaluated anastrozole $\mathrm{e}^{30,31}$ and letrozole ${ }^{32}$ for five years versus five years of tamoxifen, and both studies demonstrated an improvement in disease-free survival in favor of aromatase inhibitors (hazards ratio [HR] for anastrozole: $0.87,95 \% \mathrm{CI}$ 0.78-0.97; $P=0.01$; HR for letrozole: $0.82,95 \%$ CI $0.71-0.95$; $P=0.007)$. However, both studies failed to yield any difference in overall survival. Interestingly, the letrozole trial (BIG 1-98 trial) also evaluated the sequential approach (2-3 years of tamoxifen followed by letrozole for a total of five years or three years letrozole upfront followed by tamoxifen for a total of five years), but data from these arms are not yet available.

A randomized Phase III trial randomized 4,724 patients to exemestane after 2-3 years of tamoxifen or to continue tamoxifen for a total of five years ${ }^{34}$ and demonstrated a significant prolongation of progression-free survival in favor of exemestane (HR: 0.76, 95\% CI 0.66-0.88; $P=0.0001$ ). ${ }^{33,34}$ Similarly, a combined analysis of the Austrian Breast and Colorectal Cancer Study Group (ABCSG) trial 8 and the Arimidex-Nolvadex (ARNO 95) trial revealed a significant $40 \%$ reduction in the risk of relapse when anastrozole was administered after two years of tamoxifen, compared with five years of tamoxifen (HR: 0.60, 95\% CI 0.44-0.81; $P=0.0009) .{ }^{35}$ Finally, a smaller Italian study demonstrated a statistically significant benefit in terms of progression-free survival in favor of the switching strategy. ${ }^{36,37}$

The National Cancer Institute of Canada (NCIC) MA 17 trial randomized 5,187 patients to letrozole for five years or to placebo, after completion of five years of tamoxifen. ${ }^{39,75}$ The study was terminated early, when a planned interim analysis demonstrated a significant improvement in diseasefree survival in favor of letrozole, which was confirmed after a longer followup (HR: 0.58, 95\% CI 0.45-0.76; $P<0.0001)^{75}$ Likewise, a study from the National Surgical Adjuvant Breast and Bowel Project B-33 study asked a similar question using exemestane and revealed a trend towards higher four-year progression-free survival in favor of exemestane (HR: 0.68, $P=0.07) .{ }^{40}$ Finally, an ABCSG trial tested extended treatment with three years of anastrozole in approximately 900 patients and revealed a borderline statistically significant improvement in disease-free survival in favor of extended treatment (HR: $0.64,95 \%$ CI $0.41-0.99 ; P=0.048) .{ }^{38}$

A detailed economic analysis evaluated these three different therapeutic approaches in terms of QALYs gained versus tamoxifen (or placebo in the case of extended therapy after five years of tamoxifen). ${ }^{123}$ The analysis used a state transition model (Markov) approach to simulate the disease outcomes of patients up to a time horizon of 35 years post-surgery. The cost-effectiveness results when anastrozole or letrozole were used upfront versus tamoxifen were estimated to be $£ 32,000$ and $£ 21,600$ per QALY, respectively. In the case of the sequential strategy, data are available only for anastrozole and exemestane. (As mentioned above, the BIG 1-98 trial, which is evaluating the sequential approach for letrozole, has not yet published results for the sequential arm.) The cost-effectiveness results for the sequential approach were estimated to be $£ 23,200$ and $£ 19,200$ per QALY for anastrozole and exemestane, respectively. Finally, in the extended adjuvant setting, data were available only for letrozole and the cost per QALY was calculated to be $£ 9,800$.

In these estimations it was assumed that the benefit of aromatase inhibitors observed during the study period was gradually lost during the following 10 years (meaning that it was assumed that after the study period the recurrence rate would be significantly higher for aromatase inhibitors compared with tamoxifen and that at year 15 the number of patients without disease recurrence would be similar in the aromatase inhibitor and tamoxifen arms). When an alternative scenario with "benefits maintained" was tested, the cost-effectiveness was reduced by almost $50 \%$ to approximately $£ 10,000-12,000$, $£ 5,000$ and $£ 3,000$ for the upfront, sequential, and extended approaches, respectively. ${ }^{123}$

\section{Premenopausal}

Concerning premenopausal women, the optimal management of endocrine-responsive early breast cancer remains controversial. Tamoxifen is the gold standard for hormone receptor-positive early breast cancer. ${ }^{28}$ Oophorectomy with either ablation or suppression using a luteinising hormone-releasing hormone (LHRH) analog results in a reduction of approximately $30 \%$ in breast cancer recurrence and mortality. ${ }^{6}$ The combination of ovarian suppression with the use of LHRH analogs and tamoxifen is a widely used approach; however, it is not clear whether this combination 
offers a benefit compared with tamoxifen alone. ${ }^{6,124}$ Although aromatase inhibitors have shown benefits superior to those of tamoxifen in postmenopausal women, ${ }^{19}$ their benefits in premenopausal women are unknown. In premenopausal women, the use of aromatase inhibitors leads to an increase in gonadotropin secretion, because of the reduced feedback of estrogens to the hypothalamus and pituitary, and a subsequent stimulation of ovarian activity. ${ }^{27}$ The combination of aromatase inhibitors with a GnRH analog can achieve complete estrogen blockade by suppression of ovarian function and of peripheral estrogen synthesis. ${ }^{27}$

A recently published Phase III trial evaluated the role of LHRH combined with either tamoxifen or anastrozole as adjuvant treatment in 1803 premenopausal women. ${ }^{41}$ Patients were also randomized to receive zoledronic acid or not. The primary endpoint of the trial was disease-free survival. There was no significant difference in disease-free survival between the anastrozole and tamoxifen groups (HR: 1.10, 95\% CI $0.78-1.53 ; P=0.59)$. In contrast, the addition of zoledronic acid to endocrine therapy, as compared with endocrine therapy without zoledronic acid, resulted in an absolute reduction of 3.2 percentage points and a relative reduction of $36 \%$ in the risk of disease progression (HR: $0.64,95 \%$ CI $0.46-0.91 ; P=0.01)$. The small amount of data available about the role of aromatase inhibitors in the adjuvant treatment of premenopausal women and the small followup period preclude the drawing of any solid conclusions. Additionally, no pharmacoeconomic data exist concerning this approach. However, given the fact that the above-mentioned study yielded no difference between the two arms in terms of disease-free survival or toxicity, and given that anastrozole is more expensive than tamoxifen, a cost-minimization analysis would likely yield tamoxifen as the treatment of choice.

\section{Advanced disease setting Postmenopausal}

Tamoxifen has until recently been considered the drug of choice for first-line endocrine therapy in postmenopausal women, due to its efficacy and low toxicity. However, a number of Phase III studies have demonstrated that aromatase inhibitors are superior to tamoxifen as first-line therapy in postmenopausal women with advanced breast cancer. ${ }^{42-46}$ Although a meta-analysis of published randomized trials demonstrated a progression-free survival benefit (HR: 0.78, $95 \%$ CI $0.70-0.86$ ), there was no overall survival benefit. ${ }^{125}$ In the second-line setting, anastrozole, letrozole, and exemestane have all been shown to offer efficacy and tolerability advantages over megestrol acetate, the previous standard second-line endocrine therapy, in tamoxifen-resistant patients with hormone-dependent advanced breast cancer. ${ }^{126-129}$ On the basis of these trials, aromatase inhibitors are recommended for postmenopausal women with estrogen receptor-positive breast cancer who have not previously received endocrine treatment or who have been previously treated with tamoxifen. For postmenopausal women who are antiestrogen naïve or who have relapsed more than one year after previous treatment, aromatase inhibitors appear to have superior outcomes compared with tamoxifen, although the differences are modest.

Results of the economic analysis indicate that letrozole is a cost-effective alternative first-line therapy compared with tamoxifen for postmenopausal women with advanced breast cancer, achieving additional life-years with a modest increase in costs, having a mean incremental cost per LYG of $£ 2,342 .{ }^{130}$ The incremental costs in the comparison between letrozole or anastrozole and tamoxifen were below $£ 5,075$ per LYG and £9,200 per QALY. ${ }^{131}$ Similarly, results obtained for letrozole, anastrozole, or exemestane when used as second-line treatment versus megestrol revealed a maximum incremental cost-effectiveness ratio of $£ 9,667$ per LYG.

\section{Premenopausal}

The role of aromatase inhibitors in combination with an LHRH analog as first-line treatment has been evaluated in the context of Phase II trials. ${ }^{132,133}$ However, there is only limited experience and a small amount of data to draw on, and further research is needed before this treatment can generally be recommended.

\section{Trastuzumab versus chemotherapy}

In Italy, standard chemotherapy was compared with 12-month adjuvant trastuzumab therapy. The incremental cost-utility ratio was $€ 14,861$ per QALY gained. Based on these results the conclusion was that in the long term trastuzumab is a cost-effective alternative. ${ }^{134}$ In Norway the study was carried out with a societal perspective. In a 10-year time horizon, the cost per QALY ranged from $€ 10,185$ to $€ 37,862$ according to the overall improvement in survival. The authors suggested that trastuzumab may be cost-effective, provided that a minimum of $8 \%$ improvement in overall survival is accomplished. ${ }^{135}$

\section{Conclusions}

Significant progress has been made in the treatment of breast cancer during the last decade. Recent data support 
the use of aromatase inhibitors in the treatment of estrogen receptor-positive breast cancer, either in the adjuvant or in the advanced disease setting, at least for postmenopausal women, while for premenopausal patients data exist only for the adjuvant setting. Newer and more effective chemotherapy regimens have been tested in the early disease setting. Trastuzumab is a standard of care in the treatment of Her-2 positive disease, in either the adjuvant or advanced disease setting. Recently, bevacizumab has been proven to offer a benefit in combination with chemotherapy. Furthermore, pharmacoeconomic analysis yielded that. Despite their cost, these drugs are in general cost-effective, in various settings and countries, with incremental cost-effectiveness ratios in line with those of many other reimbursed therapies.

However, a number of significant questions still remain unanswered. Which approach is the most effective in the adjuvant setting in postmenopausal women: up-front aromatase inhibitors, sequential, or extended after five years of tamoxifen? Could aromatase inhibitors in combination with LHRH analogs represent a "standard" option in premenopausal women in either the adjuvant or the advanced disease setting? Which is the "optimal" approach in the adjuvant treatment of early breast cancer? Is sequential chemotherapy a better approach than combination treatment in advanced disease? It is clear that prospective trials are needed to answer these questions. Many clinical trials are currently evaluating these research questions. It is hoped that one or more of these approaches will prove successful and lead to substantial progress in the treatment of this common and fatal disease. Pharmacoeconomic analyses of all alternative therapy options will improve decision-making and will help decision-makers to optimize the use of scarce health care resources allocated to the treatment of cancer and the care of patients.

\section{Disclosures}

The authors report no conflict of interest in this work.

\section{References}

1. Ferlay J, Autier P, Boniol M, Heanue M, Colombet M, Boyle P. Estimates of the cancer incidence and mortality in Europe in 2006. Ann Oncol. 2007;18(3):581-592.

2. Jemal A, Siegel R, Ward E, Hao Y, Xu J, Thun MJ. Cancer Statistics, 2009. CA Cancer J Clin. 2009;59(4):225-249.

3. Berrino F, De AR, Sant M, et al. Survival for eight major cancers and all cancers combined for European adults diagnosed in 1995-99: Results of the EUROCARE-4 study. Lancet Oncol. 2007;8(9): 773-783.

4. Parkin DM, Bray F, Ferlay J, Pisani P. Global cancer statistics, 2002. CA Cancer J Clin. 2005;55(2):74-108.
5. Wood RB, Muss H, Solin LJ, Olopade OI. Malignant tumors of the breast. In: DeVita VT, Hellman S, Rosenberg SA, editors. Principles and Practice of Oncology. 7th ed. Philadelphia, PA: Lippincott, Williams \& Wilkins; 2005. p.1415-1477.

6. Effects of chemotherapy and hormonal therapy for early breast cancer on recurrence and 15-year survival: An overview of the randomised trials. Lancet. 2005;365(9472):1687-1717.

7. Key TJ, Verkasalo PK, Banks E. Epidemiology of breast cancer. Lancet Oncol. 2001;2(3):133-140.

8. Anderson WF, Chatterjee N, Ershler WB, Brawley OW. Estrogen receptor breast cancer phenotypes in the Surveillance, Epidemiology, and End Results database. Breast Cancer Res Treat. 2002;76(1):27-36.

9. Campbell J, Scott R. The costs of treating breast cancer in the US: A synthesis of published evidence. Pharmacoeconomics. 2009;27(3):199-209.

10. Barron J. Quimbo R, Nikam P, Amonkar M. Assessing the economic burden of breast cancer in a US managed care population. Breast Cancer Res Treat. 2008;109(2):367-377.

11. Max W, Sung HY, Stark B. The economic burden of breast cancer in California. Breast Cancer Res Treat. 2009;116(1):201-207.

12. Lidgren M, Wilking N, Jonsson B, Rehnberg C. Resouce use and costs associated with different states of breast cancer. Int J Technol Assess Health Care. 2007;23(2):223-231.

13. Lidgren M, Wilking N, Jonnson B. Cost of breast cancer in Sweden in 2002. Eur J Health Econ. 2007;8(1):5-15.

14. Pelletier EM, Shim B, Goodman S, Amonkar MM. Epidemiology and economic burden of brain metastases among patients with primary breast cancer: Results from a US claims data analysis. Breast Cancer Res Treat. 2008;108(2):297-305.

15. Delea T, MacKeirnan J, Brandman J, et al. Retrospective study of the effect of skeletal complications on total medical care costs in patients with bone metastases of breast cancer seen in typical clinical practice. J Support Oncol. 2006;4(7):341-347.

16. Rao S, Kubisiak J, Gilden D. Cost of illness associated with metastatic breast cancer. Breast Cancer Res Treat. 2004;83(1):25-32.

17. Hensley ML, Dowell J, Herndon JE 2nd, et al. Economic outcomes of breast cancer survivorship: CALGB study 79804. Breast Cancer Res Treat. 2005;91(2):153-161.

18. Lamerato L, Havstad S, Gandhi S, Jones D, Nathanson D. Economic burden associated with breast cancer reoccurrence: Findings from a retrospective analysis on health system data. Cancer. 2006;106(9): 1875-1882.

19. Simmons RM, Adamovich TL. Skin-sparing mastectomy. Surg Clin North Am. 2003;83(4):885-899.

20. Fisher B, Anderson S, Redmond CK, Wolmark N, Wickerham DL, Cronin WM. Reanalysis and results after 12 years of follow-up in a randomized clinical trial comparing total mastectomy with lumpectomy with or without irradiation in the treatment of breast cancer. $N$ Engl J Med. 1995;333(22):1456-1461.

21. Fisher B, Anderson S, Bryant J, et al. Twenty-year follow-up of a randomized trial comparing total mastectomy, lumpectomy, and lumpectomy plus irradiation for the treatment of invasive breast cancer. $N E n g l$ J Med. 2002;347(16):1233-1241.

22. Veronesi U, Cascinelli N, Mariani L, et al. Twenty-year follow-up of a randomized study comparing breast-conserving surgery with radical mastectomy for early breast cancer. $N$ Engl J Med. 2002;347(16):1227-1232.

23. van Dongen JA, Voogd AC, Fentiman IS, et al. Long-term results of a randomized trial comparing breast-conserving therapy with mastectomy: European Organization for Research and Treatment of Cancer 10801 trial. J Nat Cancer Inst. 2000;92(14):1143-1150.

24. Jacobson JA, Danforth DN, Cowan KH, et al. Ten-year results of a comparison of conservation with mastectomy in the treatment of stage I and II breast cancer. N Engl J Med. 1995;332(14):907-911.

25. Lyman GH, Giuliano AE, Somerfield MR, et al. American Society of Clinical Oncology guideline recommendations for sentinel lymph node biopsy in early-stage breast cancer. J Clin Oncol. 2005;23(30): 7703-7720. 
26. Goldhirsch A, Ingle JN, Gelber RD, Coates AS, Thurlimann B, Senn HJ. Thresholds for therapies: Highlights of the St Gallen International Expert Consensus on the primary therapy of early breast cancer 2009. Ann Oncol. 2009;20(8):1319-1329.

27. Smith IE, Dowsett M. Aromatase inhibitors in breast cancer. $N$ Engl $J$ Med. 2003;348(24):2431-2442.

28. Parton M, Smith IE. Controversies in the management of patients with breast cancer: Adjuvant endocrine therapy in premenopausal women. J Clin Oncol. 2008;26(5):745-752.

29. Lin NU, Winer EP. Advances in adjuvant endocrine therapy for postmenopausal women. J Clin Oncol. 2008;26(5):798-805.

30. Baum M, Budzar AU, Cuzick J, et al. Anastrozole alone or in combination with tamoxifen versus tamoxifen alone for adjuvant treatment of postmenopausal women with early breast cancer: First results of the ATAC randomised trial. Lancet. 2002;359(9324):2131-2139.

31. Howell A, Cuzick J, Baum M, et al. Results of the ATAC (Arimidex, Tamoxifen, Alone or in Combination) trial after completion of 5 years' adjuvant treatment for breast cancer. Lancet. 2005;365(9453): $60-62$.

32. Thurlimann B, Keshaviah A, Coates AS, et al. A comparison of letrozole and tamoxifen in postmenopausal women with early breast cancer. N Engl J Med. 2005;353(26):2747-2757.

33. Coombes RC, Hall E, Gibson LJ, et al. A randomized trial of exemestane after two to three years of tamoxifen therapy in postmenopausal women with primary breast cancer. N Engl J Med. 2004;350(11):1081-1092.

34. Coombes RC, Kilburn LS, Snowdon CF, et al. Survival and safety of exemestane versus tamoxifen after 2-3 years' tamoxifen treatment (Intergroup Exemestane Study): A randomised controlled trial. Lancet. 2007;369(9561):559-570.

35. Jakesz R, Jonat W, Gnant M, et al. Switching of postmenopausal women with endocrine-responsive early breast cancer to anastrozole after 2 years' adjuvant tamoxifen: Combined results of ABCSG trial 8 and ARNO 95 trial. Lancet. 2005;366(9484):455-462.

36. Boccardo F, Rubagotti A, Puntoni M, et al. Switching to anastrozole versus continued tamoxifen treatment of early breast cancer: Preliminary results of the Italian Tamoxifen Anastrozole Trial. J Clin Oncol. 2005;23(22):5138-5147.

37. Boccardo F, Rubagotti A, Guglielmini P, et al. Switching to anastrozole versus continued tamoxifen treatment of early breast cancer. Updated results of the Italian tamoxifen anastrozole (ITA) trial. Ann Oncol. 2006; Suppl 7:vii10-vii14.

38. Jakesz R, Greil R, Gnant M, et al. Extended adjuvant therapy with anastrozole among postmenopausal breast cancer patients: Results from the randomized Austrian Breast and Colorectal Cancer Study Group Trial 6a. J Natl Cancer Inst. 2007;99(24):1845-1853.

39. Goss PE, Ingle JN, Martino S, et al. A randomized trial of letrozole in postmenopausal women after five years of tamoxifen therapy for earlystage breast cancer. $N$ Engl J Med. 2003;349(19):1793-1802.

40. Mamounas EP, Jeong JH, Wickerham DL, et al. Benefit from exemestane as extended adjuvant therapy after 5 years of adjuvant tamoxifen: Intention-to-treat analysis of the National Surgical Adjuvant Breast And Bowel Project B-33 trial. J Clin Oncol. 2008;26(12): 1965-1971.

41. Gnant M, Mlineritsch B, Schippinger W, et al. Endocrine therapy plus zoledronic acid in premenopausal breast cancer. $N$ Engl $J$ Med. 2009;360(7):679-691.

42. Bonneterre J, Thurlimann B, Robertson JF, et al. Anastrozole versus tamoxifen as first-line therapy for advanced breast cancer in 668 postmenopausal women: Results of the Tamoxifen or Arimidex Randomized Group Efficacy and Tolerability study. J Clin Oncol. 2000;18(22):3748-3757.

43. Mouridsen H, Gershanovich M, Sun Y, et al. Superior efficacy of letrozole versus tamoxifen as first-line therapy for postmenopausal women with advanced breast cancer: Results of a phase III study of the International Letrozole Breast Cancer Group. J Clin Oncol. 2001;19(10):2596-2606.
44. Nabholtz JM, Buzdar A, Pollak M, et al. Anastrozole is superior to tamoxifen as first-line therapy for advanced breast cancer in postmenopausal women: Results of a North American multicenter randomized trial. Arimidex Study Group. J Clin Oncol. 2000;18(22): $3758-3767$.

45. Vergote I, Bonneterre J, Thurlimann B, et al. Randomised study of anastrozole versus tamoxifen as first-line therapy for advanced breast cancer in postmenopausal women. Eur J Cancer. 2000;36 Suppl 4:S84-S85.

46. Paridaens RJ, Dirix LY, Beex LV, et al. Phase III study comparing exemestane with tamoxifen as first-line hormonal treatment of metastatic breast cancer in postmenopausal women: The European Organisation for Research and Treatment of Cancer Breast Cancer Cooperative Group. J Clin Oncol. 2008;26(30):4883-4890.

47. Jonat $\mathrm{W}$, Gnant $\mathrm{M}$, Boccardo $\mathrm{F}$, et al. Effectiveness of switching from adjuvant tamoxifen to anastrozole in postmenopausal women with hormone-sensitive early-stage breast cancer: A meta-analysis. Lancet Oncol. 2006;7(12):991-996.

48. NCCN Clinical Practice Guidelines in Oncology. Volume 1. 2009. Breast Cancer. Available from: http://www.nccn.org/professionals/physician_gls/f_guidelines.asp. Accessed Mar 9, 2010.

49. Sotiriou C, Pusztai L. Gene-expression signatures in breast cancer. N Engl J Med. 2009;360(8):790-800.

50. De Laurentiis M, Cancello G, D'Agostino D, et al. Taxane-based combinations as adjuvant chemotherapy of early breast cancer: A meta-analysis of randomized trials. J Clin Oncol. 2008;26(1):44-53.

51. Cardoso F, Bedard PL, Winer EP, et al. International guidelines for management of metastatic breast cancer: Combination vs sequential single-agent chemotherapy. J Natl Cancer Inst. 2009;101(17): 1174-1181.

52. Carrick S, Parker S, Wilcken N, Ghersi D, Marzo M, Simes J. Single agent versus combination chemotherapy for metastatic breast cancer. Cochrane Database Syst Rev. 2005;(2):CD003372.

53. Sledge GW, Neuberg D, Bernardo P, et al. Phase III trial of doxorubicin, paclitaxel, and the combination of doxorubicin and paclitaxel as front-line chemotherapy for metastatic breast cancer: An intergroup trial (E1193). J Clin Oncol. 2003;21(4):588-592.

54. O'Shaughnessy J, Miles D, Vukelja S, et al. Superior survival with capecitabine plus docetaxel combination therapy in anthracycline-pretreated patients with advanced breast cancer: Phase III trial results. J Clin Oncol. 2002;20(12):2812-2823.

55. Miller K, Wang M, Gralow J, et al. Paclitaxel plus bevacizumab versus paclitaxel alone for metastatic breast cancer. $N$ Engl $J$ Med. 2007;357(26):2666-2676

56. Harris L, Fritsche H, Mennel R, et al. American Society of Clinical Oncology 2007 update of recommendations for the use of tumor markers in breast cancer. J Clin Oncol. 2007;25(33):5287-5312.

57. Slamon DJ, Leyland-Jones B, Shak S, et al. Use of chemotherapy plus a monoclonal antibody against HER 2 for metastatic breast cancer that overexpresses HER-2. N Engl J Med. 2001;344(11):783-792.

58. Seidman AD, Berry D, Cirrincione C, et al. Randomized phase III trial of weekly compared with every-3-weeks paclitaxel for metastatic breast cancer, with trastuzumab for all HER-2 overexpressors and random assignment to trastuzumab or not in HER-2 nonoverexpressors: Final results of Cancer and Leukemia Group B protocol 9840. J Clin Oncol. 2008;26(10):1642-1649.

59. Robert N, Leyland-Jones B, Asmar L, et al. Randomized phase III study of trastuzumab, paclitaxel, and carboplatin compared with trastuzumab and paclitaxel in women with HER-2-overexpressing metastatic breast cancer. J Clin Oncol. 2006;24(18):2786-2792.

60. Burstein HJ, Keshaviah A, Baron AD, et al. Trastuzumab plus vinorelbine or taxane chemotherapy for HER2-overexpressing metastatic breast cancer: The trastuzumab and vinorelbine or taxane study. Cancer. 2007;110(5):965-972.

61. Vogel CL, Cobleigh MA, Tripathy D, et al. Efficacy and safety of trastuzumab as a single agent in first-line treatment of HER-2- overexpressing metastatic breast cancer. J Clin Oncol. 2002;20(3):719-726. 
62. Bartsch R, Wenzel C, Altorjai G, et al. Capecitabine and trastuzumab in heavily pretreated metastatic breast cancer. J Clin Oncol. 2007;25(25):3853-3858.

63. von MG, du BA, Schmidt M, Maass N, Cufer T, de Jongh FE, et al. Trastuzumab beyond progression in human epidermal growth factor receptor 2-positive advanced breast cancer: German breast group 26/breast international group 03-05 study. J Clin Oncol. 2009;27(12):1999-2006.

64. Geyer CE, Forster J, Lindquist D, et al. Lapatinib plus capecitabine for HER-2-positive advanced breast cancer. $N$ Engl J Med. 2006;355(26):2733-2743.

65. O’Shaughnessy J, Blackwell KL, Burstein H, et al. A randomized study of lapatinib alone or in combination with trastuzumab in heavily pretreated HER-2+ metastatic breast cancer progressing on trastuzumab therapy. J Clin Oncol. 2009;26(20 Suppl):Abstr 1015.

66. Romond EH, Perez EA, Bryant J, et al. Trastuzumab plus adjuvant chemotherapy for operable HER2-positive breast cancer. N Engl J Med. 2005;353(16):1673-1684.

67. Piccart-Gebhart MJ, Procter M, et al. Trastuzumab after adjuvant chemotherapy in HER-2-positive breast cancer. $N$ Engl J Med. 2005;353(16):1659-1672.

68. Joensuu H, Kellokumpu-Lehtinen PL, Bono P, et al. Adjuvant docetaxel or vinorelbine with or without trastuzumab for breast cancer. $N E n g l J$ Med. 2006;354(8):809-820.

69. Robert NJ, Eirmann W, Pienkowski T, et al. BCIRG 006: Docetaxel and trastuzumab-based regimens improve DFS and OS over AC-T in node positive and high risk node negative HER2 positive early breast cancer patients: Quality of life (QOL) at 36 months follow-up. J Clin Oncol. 2007;25(18S):Abstr 19647.

70. Hillner BE, Ingle JN, Chlebowski RT, et al. American Society of Clinical Oncology 2003 update on the role of bisphosphonates and bone health issues in women with breast cancer. J Clin Oncol. 2003;21(21):40424057.

71. Theriault RL, Lipton A, Hortobagyi GN, et al. Pamidronate reduces skeletal morbidity in women with advanced breast cancer and lytic bone lesions: A randomized, placebo-controlled trial. Protocol 18 Aredia Breast Cancer Study Group. J Clin Oncol. 1999;17(3):846-854.

72. Rosen LS, Gordon DH, Dugan W Jr, et al. Zoledronic acid is superior to pamidronate for the treatment of bone metastases in breast carcinoma patients with at least one osteolytic lesion. Cancer. 2004;100(1):3643.

73. Diel IJ, Body JJ, Lichinitser MR, et al. Improved quality of life after long-term treatment with the bisphosphonate ibandronate in patients with metastatic bone disease due to breast cancer. Eur J Cancer. 2004;40(11):1704-1712.

74. Folkestad L, Bjarnason NH, Bjerregaard JK, Brixen K. The effect of aromatase inhibitors on bone metabolism. Basic Clin Pharmacol Toxicol. 2009;104(1):3-10.

75. Goss PE, Ingle JN, Martino S, et al. Randomized trial of letrozole following tamoxifen as extended adjuvant therapy in receptor-positive breast cancer: Updated findings from NCIC CTG MA17. J Natl Cancer Inst. 2005;97(17):1262-1271.

76. Perez EA, Suman VJ, Davidson NE, et al. Cardiac safety analysis of doxorubicin and cyclophosphamide followed by paclitaxel with or without trastuzumab in the North Central Cancer Treatment Group N9831 adjuvant breast cancer trial. J Clin Oncol. 2008;26(8): 1231-1238.

77. Tan-Chiu E, Yothers G, Romond E, et al. Assessment of cardiac dysfunction in a randomized trial comparing doxorubicin and cyclophosphamide followed by paclitaxel, with or without trastuzumab as adjuvant therapy in node-positive, human epidermal growth factor receptor 2-overexpressing breast cancer: NSABP B-31. J Clin Oncol. 2005;23(31):7811-7819.

78. Telli ML, Hunt SA, Carlson RW, Guardino AE. Trastuzumab-related cardiotoxicity: Calling into question the concept of reversibility. J Clin Oncol. 2007;25(23):3525-3533.
79. Lin NU, Winer EP. Brain metastases: The HER-2 paradigm. Clin Cancer Res. 2007;13(6):1648-1655.

80. Eckermann SD, Martin AJ, Stockler MR, Simes RJ. The benefits and costs of tamoxifen for breast cancer prevention. Aust $N$ Z J Public Health. 2003;27(1):34-40.

81. Karnon J, Brown J on behalf of the ABC Steering Committee. Tamoxifen plus chemotherapy versus tamoxifen alone as adjuvant therapies for node-positive postmenopausal women with early breast cancer: A stochastic evaluation. Pharmacoeconomics. 2002;20(2): 119-137.

82. Thompson D, Taylor DC, Montoya EL, Winer EP, Jones SE, Weinstein MC. Cost effectiveness of switching to exemestane after 2 to 3 years of therapy with tamoxifen in postmenopausal women with early stage breast cancer. Value in Health. 2007;10(5):367-376.

83. Risebrough NA, Verma S, Trudeau M, Mittmann N. Cost effectiveness of switching to exemestane versus continued tamoxifen as adjuvant therapy for post menopausal women with primary breast cancer. Cancer. 2007;110(3):499-508.

84. Lundkvist J, Wilking N, Holmberg S, Jonnson L. Cost-effectiveness of exemestane versus tamoxifen as adjuvant therapy for early stage breast cancer after 2-3 years treatment with tamoxifen in Sweden. Breast Cancer Res Treat. 2007;102(3):289-299.

85. Hillner BE, Radice D. Cost effectiveness of exemestane compared with megestrol in patients with advanced breast carcinoma. Cancer. 2001;91(3):484-489.

86. Lindgren P, Jonsson B. Radaelli A, Radice D. Cost effectiveness analysis of exemestane compared with megestrol in advanced breast cancer: A model for Europe and Australia. Pharmacoeconomics. 2002;20(2):101-108.

87. Nuijten M, Meester L, Waibel F, Wait S. Cost effectiveness of letrozole in the treatment of advanced breast cancer in postmenopausal women in the UK. Pharmacoeconomics. 1999;16(4):379-397.

88. Ward S, Simpson E, Davis S, Hind D, Rees A, Wilkinson A. Taxanes for the adjuvant treatment of early breast cancer: Systematic review and economic evaluation. Health Technol Assess. 2007;11(40):1-144.

89. Limwattananon S, Limwattananon C, Maoleekulpairoj S, Soparatanapaisal N. Cost effectiveness analysis of sequential paclitaxel adjuvant chemotherapy for patients with node positive primary breast cancer. $J$ Medical Assoc Thai. 2006;89(5):690-698.

90. Brown RE, Hutton J, Burrell A. Cost effectiveness of treatment options in advanced breast cancer in the UK. Pharmacoeconomics. 2001;19(11):1091-1102.

91. Leung PP, Tannock IF, Oza AM, Puodziunas A, Dranitsaris G. Cost-utility analysis of chemotherapy using paclitaxel, docetaxel or vinorelbine for patients with anthracycline-resistant breast cancer. J Clin Oncol. 1999;17(10):3082-3090.

92. Vu T, Ellard S, Speers CH, et al. Survival outcome and cost-effectiveness with docetaxel and paclitaxel in patients with metastatic breast cancer: A population based evaluation. Ann Oncol. 2008;19(3): $461-464$.

93. Li N, van Agthoven M, Willemse PH, Uyl-de Groot CA. A cost-utility analysis comparing second line chemotherapy schemes in patients with metastatic breast cancer. Anti-Cancer Drugs. 2001;12(6):533-540.

94. Verma S, Illersich AL. Population based pharmacoeconomic model for adopting capecitabine/docetaxel combination treatment for anthracyclinepretreated metastatic breast cancer. Oncologist. 2003;8(3):232-240.

95. Ravasio R, Giuliani G, Veronesi A. Cost-efficacy of capecitabine and docetaxel in combination compared with docetaxel monotherapy in patients with metastatic breast cancer pre-treated with anthracyclines. Pharmacoeconomics. 2005;7(1):59-66.

96. Verma S, Maraninchi D, O’Shaughnessy J, et al. Capecitabine plus docetaxel combination therapy. Cancer. 2005;103(12):2455-2465.

97. Takeda AL, Jones J, Loveman E, Tan SC, Clegg AJ. The clinical effectiveness and cost-effectiveness of gemcitabine for metastatic breast cancer: A systematic review and economic evaluation. Health Technol Assess. 2007;11(19):iii, ix-xi, 1-62. 
98. National Institute for Health and Clinical Excellence. Advanced breast cancer: Diagnosis and treatment. NICE technology appraisal guidance. Number 62, 2009. Available from: www.nice.org.uk/pdf/Breast cancerlapatinibFAD.pdf. Accessed March 07, 2010.

99. Chan AL, Leung HW, Lu CL, Lin SJ. Cost-effectiveness of trastuzumab as adjuvant therapy for early breast cancer: A systematic review. Ann Pharmacother. 2009;43(2):296-303.

100. National Institute for Health and Clinical Excellence. Trastuzumab for the adjuvant treatment of early stage HER2-positive breast cancer. NICE technology appraisal guidance. 2006. Available from: www. nice.org.uk/nicemedia/pdf/TA107guidance.pdf. Accessed March 9, 2010 .

101. Van V I, Canon JL, Cocquyt V, et al. Trastuzumab treatment of early stage breast cancer is cost-effective from the perspective of the Belgian health care authorities. Acta Clin Belg. 2009;64(2):100-112.

102. Neyt M, Huybrechts M, Hulstaert F, Vrijens F, Ramaekers D. Trastuzumab in early stage breast cancer: A cost effectiveness analysis for Belgium. Health Policy. 2008;87:146-159.

103. Millar JA, Millward MJ, Cost effectiveness of trastuzumab in the adjuvant treatment of early breast cancer: A lifetime model. Pharmacoeconomics. 2007;25(5):429-442.

104. Botteman M, Barghout V, Stephens J, Hay J, Brandman J, Aapro M. Cost effectiveness of bisphsphonates in the management of breast cancer patients with bone metastases. Ann Oncol.2006;17(7): 1072-1082.

105. Guest JF, Clegg JP, Davie AM, McCloskey E. Costs and consequences of using pamidronate compared with zoledronic acid in the management of breast cancer patients in the UK. Curr Med Res Opin. 2005;21(5): 805-815.

106. Slof J, Badia X, Lizan L, et al. Zoledronic acid versus pamidronate: Cost-minimization in bone metastasis. J Med Econ. 2005;8:1-12.

107. De Cock E, Hutton J, Canney P, Body JJ, Barrett-Lee MP, Lewis G. Cost-effectiveness of oral ibandronate versus IV zoledronic acid or IV pamidronate for bone metastases in patients receiving oral hormonal therapy for breast cancer in the United Kingdom. Clin Ther. 2005;27(8):1295-1310.

108. Reed SD, Radeva JI, Glendenning GA, Coleman RE, Schulman KA. Economic evaluation of zoledronic acid versus pamidronate for the prevention of skeletal-related events in metastatic breast cancer and multiple myeloma. Am J Clin Oncol. 2005;28(1):8-16.

109. Hillner BE, Weeks JC, Desch CE, Smith TJ. Pamidronate in prevention of bone complications in metastatic breast cancer: A cost-effectiveness analysis. J Clin Oncol. 2000;18(1):72-79.

110. Dranitsaris G. Hsu T. Cost utility analysis of prophylactic pamidronate for the prevention of skeletal related events in patients with advanced breast cancer. Support Care Cancer. 1999;7(4):271-279.

111. Body JJ. Effectiveness and cost of bisphosphonate therapy in tumor bone disease. Cancer. 2003;97(3 Suppl):859-865.

112. Burdette-Radoux S, Muss HB. A question of duration: Do patients with early-stage breast cancer need more than five years of adjuvant endocrine therapy? Clin Breast Cancer. 2009;9 Supp1 1:S37-S41.

113. Delea TE, El-Ouagari K, Karnon J, Sofrygin O. Cost-effectiveness of letrozole versus tamoxifen as initial adjuvant therapy in postmenopausal women with hormone-receptor positive early breast cancer from a Canadian perspective. Breast Cancer Res Treat. 2008;108(3):375-387.

114. Ouagari KE, Karnon J, Delea T, Talbot W, Brandman J. Cost-effectiveness of letrozole in the extended adjuvant treatment of women with early breast cancer. Breast Cancer Res Treat. 2007;101(1):37-49.

115. Karnon J, Johnston SR, Jones T, Glendenning A. A trial based cost effectiveness analysis of letrozole followed by tamoxifen versus tamoxifen followed by letrozole for postmenopausal advanced breast cancer. Ann Oncol. 2003;14(11):1629-1633.

116. Rocchi A, Verma S. Anastrozole is cost-effective vs tamoxifen as initial adjuvant therapy in early breast cancer: Canadian perspectives on the ATAC completed-treatment analysis. Support Care Cancer. 2006;14(9): 917-927.
117. Locker GY, Mansel R, Cella D, Dobrez D, Sorensen S, Gandhi SK; ATAC Trialists Group. Cost-effectiveness analysis of anastrozole versus tamoxifen as primary adjuvant therapy for postmenopausal women with early breast cancer: A US healthcare system perspective. The 5-year completed treatment analysis of the ATAC ('Arimidex', Tamoxifen Alone or in Combination) trial. Breast Cancer Res Treat. 2007;106(2):229-238.

118. Mansel R, Locker G, Fallowfield L, Benedict A, Jones D. Costeffectiveness analysis of anastrozole vs. tamoxifen in adjuvant therapy for early stage breast cancer in the United Kingdom: The 5-year completed treatment analysis of the ATAC ('Arimidex', Tamoxifen alone or in combination) trial. Br J Cancer. 2007;97(2):152-161.

119. Moeremans K, Annemans L. Cost-effectiveness of anastrozole compared to tamoxifen in hormone receptor-positive early breast cancer: Analysis based on the ATAC trial. Int J Gynecol Cancer. 2006;16(Suppl 2): 576-578.

120. Piskur P, Sonc M, Cufer T, Borstnar S, Mrhar A. Pharmacoeconomic aspects of adjuvant anastrozole or tamoxifen in breast cancer: A Slovenian perspective. Anti-Cancer Drugs. 2006;17(6): 719-724.

121. Ouagari KE, Karnon J, Delea T, Talbot W, Brandman J. Cost-effectiveness of letrozole in the extended adjuvant treatment of women with early breast cancer. Breast Cancer Res Treat. 2007;101(1):37-49.

122. Delea TE, Karnon J, Smith RE, Johnston SR, Brandman J, Sung JC, Goss PE. Cost-effectiveness of extended adjuvant letrozole therapy after 5 years of adjuvant tamoxifen therapy in postmenopausal women with early stage breast cancer. Am J Manag Care. 2006;12(7):374-386.

123. Hind D, Ward S, De NE, Simpson E, Carroll C, Wyld L. Hormonal therapies for early breast cancer: Systematic review and economic evaluation. Health Technol Assess. 2007 July;11(26):iii-xi, 1.

124. Cuzick J, Ambroisine L, Davidson N, et al. Use of luteinising-hormonereleasing hormone agonists as adjuvant treatment in premenopausal patients with hormone-receptor-positive breast cancer: A meta-analysis of individual patient data from randomised adjuvant trials. Lancet. 2007 May 19;369(9574):1711-1723.

125. Gibson LJ, Dawson CK, Lawrence DH, Bliss JM. Aromatase inhibitors for treatment of advanced breast cancer in postmenopausal women. Cochrane Database Syst Rev. 2007;(1):CD003370.

126. Buzdar A, Douma J, Davidson N, et al. Phase III, multicenter, double-blind, randomized study of letrozole, an aromatase inhibitor, for advanced breast cancer versus megestrol acetate. J Clin Oncol. 2001;19(14):3357-3366.

127. Buzdar AU, Jonat W, Howell A, et al. Anastrozole versus megestrol acetate in the treatment of postmenopausal women with advanced breast carcinoma: Results of a survival update based on a combined analysis of data from two mature phase III trials. Arimidex Study Group. Cancer. 1998;83(6):1142-1152.

128. Dombernowsky P, Smith I, Falkson G, et al. Letrozole, a new oral aromatase inhibitor for advanced breast cancer: Double-blind randomized trial showing a dose effect and improved efficacy and tolerability compared with megestrol acetate. J Clin Oncol. 1998;16(2):453-461.

129. Kaufmann M, Bajetta E, Dirix LY, Fein LE, Jones SE, Zilembo N, et al. Exemestane is superior to megestrol acetate after tamoxifen failure in postmenopausal women with advanced breast cancer: Results of a phase III randomized double-blind trial. The Exemestane Study Group. J Clin Oncol. 2000;18(7):1399-1411.

130. Karnon J, Jones T. A stochastic economic evaluation of letrozole versus tamoxifen as a first-line hormonal therapy: For advanced breast cancer in postmenopausal patients. Pharmacoeconomics. 2003;21(7): $513-525$.

131. Advanced breast cancer: Diagnosis and treatment. Full Guideline developed for NICE by the National Collaborating Centre for Cancer. February 2009. Available from: http://www.nice.org.uk/nicemedia/pdf/ CG81FullGuideline.pdf. Accessed March 9, 2010.

132. Torrisi R, Bagnardi V, Pruneri G, et al. Antitumour and biological effects of letrozole and GnRH analogue as primary therapy in premenopausal women with ER and PgR positive locally advanced operable breast cancer. Br J Cancer. 2007;97(6):802-808. 
133. Forward DP, Cheung KL, Jackson L, Robertson JF. Clinical and endocrine data for goserelin plus anastrozole as second-line endocrine therapy for premenopausal advanced breast cancer. $\mathrm{Br} J$ Cancer. 2004;90(3):590-594.

134. Liberato NL, Marchetti M, Barosi G. Cost effectiveness of adjuvant trastuzumab in human epidermal growth factor receptor 2-positive breast cancer. J Clin Oncol. 2007;25(6):625-633.
135. Norum J, Olsen JA, Wist EA, Lonning PE. Trastuzumab in adjuvant breast cancer therapy: A model based cost-effectiveness analysis. Acta Oncol. 2007;46(2):153-164.

\section{Publish your work in this journal}

OncoTargets and Therapy is an international, peer-reviewed, open access journal focusing on the pathological basis of all cancers, potential targets for therapy and treatment protocols employed to improve the management of cancer patients. The journal also focuses on the impact of management programs and new therapeutic agents and protocols on

\section{Dovepress}

patient perspectives such as quality of life, adherence and satisfaction. The manuscript management system is completely online and includes a very quick and fair peer-review system, which is all easy to use. Visit http://www.dovepress.com/testimonials.php to read real quotes from published authors.

Submit your manuscript here: http://www.dovepress.com/oncotargets-and-therapy-journal 